\title{
Creativity, Communicability and Organizational Culture: an Introduction to the Study of Hierarchy as Both a Facilitator and Constraint in Organizational Change
}

\author{
Asdrúbal Borges Formiga Sobrinho \\ Universidade de Brasília, Brazil \\ E-mail: asdru_bal@uol.com.br
}

\author{
Vlad Petre Glăveanu \\ Aalborg University, Denmark \\ E-mail address: vlad@ hum.aau.dk
}

\section{ARTICLE INFO}

\section{Keywords:}

Interpersonal communication

Communicability

Creativity

Hierarchy

Organizational culture

\section{A B STRACT}

Article history:

Received 20 September 2017

Received in revised form 22 December 2017

Accepted 23 December 2017

ISSN: 2354-0036

DOI: $10.1515 /$ ctra-2017-0010
How can hierarchy influence individual creativity in the work environment? In the contemporary literature about creativity in organizations sometimes factors like this are considered constraints. However, the question remains as to how the meaning of hierarchy can change or what causes changes in a given organizational culture. This paper aims to document these processes in a Brazilian public organization, by considering the creative actions of employees, in particular those meant to enhance communicability or the potential for making communication effective. To reach this goal, thematic content analysis was applied to individual interviews of two employees. Considering the contradictions and ambiguities in their discourses and actions, the results point to the fact that environmental factors like hierarchy can change their meaning according to employees' actions and interactions with colleagues and managers. This makes the communication stimulating or constraining for creativity, at least as expressed in the generation of new meanings or novelties. Thus, the practical question to reflect upon becomes: how can individual actions change the meaning of hierarchy and make the work environment more favorable to creativity?

\section{INTRODUCTION}

This paper is grounded in a theoretical exploration of the relation between creativity and communication in organizational contexts and constitutes an exploration of the theme for further in-depth research. How can the concepts - approached as processes - be related theoretically, based on questioning the way in which communication allows changes and other phenomena related to novelty? And how can the concepts be approached as interdependent processes observable in and through practices, after analyzing a given context of an organization, based on the speeches and other actions of its employees? 
These questions come from the assumption that communication is an essential part of the organizational culture, meaning that through it is possible to identify the principles of internal relations, their mediations and contradictions (Curvello, 2012). Communication plays a great role in constructing the overall work climate and the work climate for creativity. Considering the emphasis placed on previous studies of creativity on idea generation (Paulus, Dzindolet, \& Kohn, 2012), it's important to advance also in our understanding of the conditions not only for generating, but also for communicating and developing creative ideas in environments people spend many hours - including years - together. To answer these questions, we will begin by presenting the concepts of communication and creativity in relation to each other, followed by a description of the methodology used to study processes in the work of employees from a Brazilian public organization. This investigation is based on sociocultural approaches to culture and organizational culture, communication and creativity. The focus was on individual trajectories in the organization in relation to hierarchy and rules, two notions whose role in creative research is usually that of constraints, instead of something "upon which the creative process is built" (Juelsbo, 2016, p. 137). In the end, the findings are discussed in light of our theoretical concerns and in view of the practical implications of this research for understanding and promoting organizational change.

\section{THEORETICAL FRAME}

\section{Communication, communicability and change}

In order to understand the bi-directional links between interpersonal communication and organizational environments, it's important to start from general approaches to communication. As Martino (2001) notes, the term communication has Latin roots leading to the notion of jointly developed activities. This author traces the meaning of communication to monastic practices of eating together after spending time in isolation. Communication thus carries at least a potential for the development of activities which involve intentional purposes in interaction with other people and depends on the way participants act.

In a sociocultural and semiotic perspective, communication refers to dialogues between at least two people, dialogues which depend first on the mutual understanding of the codes used (Valsiner, 2007; Machado, 2003). However, this dialogue can involve more than two persons when considering interactions that occur in groups or mass communication contexts. In this research, however, we focus on interpersonal communication within organizational settings. According to Marcondes Filho (2016), communication can be understood as a way of transforming information cues into meaning. This already gives communication the potential to generate novelty, since, even within repeated communication, both people and meanings can change. The environment, in turn, can also 
change, through individual actions and even through the act of communication itself. Both these changes - in individual(s) and in the environment - unavoidably affect communicational processes and can lead to new meanings and actions.

However, not all communicational process lead to new meanings and it is important to consider the different purposes involved, as well as the different levels of communication, with outcomes varying from keeping to changing existing meanings. Moreover, we need to reflect on different levels of communicability, conceived as an ever-present potential to communicate effectively, shaped by and shaping the context of interaction between individuals (Thayer, 1973). In order to capture the role of communicability, initially understood as a potential of the language and linguistic processes which put people together (Marcondes Filho, 2016), in maintaining old meanings or creating new ones within acts of - in this case - interpersonal communication, we propose a typology that includes four levels, explained as follows (see also Table 1).

The first level captures the intention, in communication, to establish a certain meaning beyond contestation by using a variety of coercive and rhetorical means; for example, the appeal to the 'higher' authority of scientific truth, moral imperatives, religious dogmas, etc. These strategies are often used when speakers did not initially have the expected impact or were not able to impose their meaning or persuade others of it (Marcondes Filho, 2010) and, by this action, make the communication possible according to the intention of the speakers. As mentioned in Table 1, this communicability context has the potential to establish meanings by metaphorically 'opening the ear' of the audience (who should hear, rather than talk) but, at the same time, these meanings are likely to be 'old' or established. This level of communicability reminds one of Bakhtin's (1981) notion of the monological, whereby communication takes place more in a uni-directional manner.

The second level refers to the intention of making things 'clear' within communication, without using the appeal to authority and, as such, in a more open or dialogical manner. Metaphorically, it invites audiences to 'open their eyes' and look further into what is being communicated. This creates the possibility of generating new meanings, although partners could reverse to a level 1 context in trying to establish their own meaning and impose it on others.

At a third level, the communicability context appeals to the emotions of others and the aim is to share not only information but a certain sensation with them, within one and the same communication stream (Marcondes Filho, 2010). In the positive version, this level fosters openness within the communication partners and leads to new meanings; however, the use of emotions (expressed in laughing, crying, feeling scared, etc.) can also block new perspectives and reinforce established meanings. Metaphorically, at this 
level, partners attempt to 'open the heart' of others towards their experience (Negus \& Pickering, 2004) of the situation.

Last but not least, at the forth level the aim is to change established meanings and challenge the conventional and, as such, this communicability context is highly likely to foster the creativity, at least in attitudinal terms. These outcomes depend on the openness of each partner during communication, and on the way each one means or interprets the message. In Bakhtin's terms (1981), this is an expression of the dialogical in communication, whereby different meanings are raised and placed in productive tension with each other. Metaphorically, the aim is to 'open the mind' of the audience towards a certain issue, problem or situation.

In summary, communicability captures the main characteristics of communication processes, from their purposes to their outcomes. In its first level, it can reinforce existing meanings as a way of doing things together (Martino, 2001), although this togetherness doesn't really mean agreeing on the meanings, but maybe accepting them. In the second level, for strategically exploiting and diversifying meanings, possibly towards persuading others (Marcondes Filho, 2010). In the third, for feeling together, possibly reinforcing the meanings shared on the one hand, and, on the other hand, making people open to new meanings (Negus \& Pickering, 2004) or taking advantage of their openness for introducing new meanings. In the forth, for creating further changes in attitudes or behaviors (Bakhtin, 1981).

\section{Table 1}

Four Levels of Communicability

\begin{tabular}{lccc}
\hline Level & Potential to & Audience should & Meanings are \\
\hline 1 & establish & open the ear & probably old \\
2 & improve & open the eye & old or new \\
3 & influence & open the heart & old or new \\
4 & change & open the mind & probably new \\
\hline
\end{tabular}

\section{Creativity and communication in a sociocultural approach}

The previous typology highlights different ways in which communication and creativity relate to each other by arguing that different communicability contexts can either foster or hinder the emergence of new and useful meanings and actions, the hallmark of creativity (Eisenberg et al., 2010; Lubart, 2007). It shows that communication is an openended process depending on conditions like openness and spontaneity that are not only individual characteristics but emerging properties of interpersonal interactions. Important- 
ly, the relationship between creativity and communication is not linear or deterministic and Level 1 communicability, for instance, does not automatically exclude novelty just as Level 4 doesn't automatically produce it. In fact, as we will see in our research, hierarchy and relations of power usually associated with Level 1 communicability contexts can create the conditions for the emergence of novelty, including in how employees relate to and understand hierarchies. This means that communication processes, at all times and at all levels, are potential sources of creativity and the purpose of this research is - in the current stage - begin to investigate how they are managed by employees and how they relate to organizational change.

Before describing this dynamic, however, it is important to discuss creativity from a social and cultural perspective (Gillespie, 2010; Glăveanu et al., 2014). From this standpoint, individuals are both 'objects' and 'agents' of the social structure (Vigotski, 2000 [1929]; Vigotski, 1998; Wallon, 1979), using mediational tools such as language and other cultural resources (Lotman, 1997; Tejerina \& Rosa, 2007) to shape their environment in interaction with other people. For example, in the workplace, they are both constrained by an existing cultural and institutional structure and capable, through communication, to impact, adjust or change it. This assumption makes creativity a complex and dynamic phenomenon in organizations, where elements from the culture of the individual, group or team, organization and society all contribute to work situation. Communication contexts are capable of making the same conditions (like demands for autonomy) favorable for the creativity of an individual and detrimental for the group (Choi et al., 2009). Similarly, the same behavior which can be valued as creative by an organization, like risk taking, might not be by another (Bruno-Faria, 2003).

Thus, the contributions of cultural psychology to the psychology of creativity are very relevant for approaching communication as the negotiation of meanings in organizational contexts. This is due to the fact this theoretical perspective considers culture as more than a way to characterize those individuals who share the same values. Instead, it theorizes it as an environment that structures individual psychological systems while being open to change as a result of individual and collaborative forms of creativity (Glăveanu et al., 2012). This approach follows a dialogical model of communication in which individuals are, at once, products and producers of culture, thus, active agents in the making meaning about themselves, others, and their relationship. This meaning making process is sometimes marked by the consonance between individual and organizational repertoires and sometimes by the tensions between them, which call for creative solutions to existing problems. Typical for a sociocultural take on creativity is the fact that the origin 
of creative outcomes is not to be placed 'within' individuals or individual minds but rather in the communicative relations established between them.

Importing this logic within communication theory, we can conclude that there is a double connection between communication and creativity. On the one hand, creativity always emerges out of communicative interactions, even when the person works alone, through implicit forms of collaboration with others and their ideas (Barron, 1995). Ultimately, this makes all creative outcomes co-creations rather than products of purely individual processes and actions (Glăveanu, 2012). At the same time, creativity itself is a form of communication or expression and this can be easily understood when noticing that each creative outcome is intended for a certain audience. Reversely, communication is at least potentially creative by always being open - to different degrees, see the typology proposed in the previous section - to novelty and new meanings. What is important to investigate in research, and this is the aim of the present study, are the conditions that make certain communicability contexts foster or hinder creativity. As argued here, a sociocultural perspective always assumes that that the relation between communicability and creativity is contextual and this will be illustrated further with findings concerning the meaning and value of hierarchy.

The choice of hierarchy as a research focus is motivated by at least three main arguments. The first, general one, refers to the close connection between creativity and constraints. Indeed, as previous research argued, creativity requires constraints (see Sternberg \& Kaufman, 2010) and it also emerges out of constraints, including selfimposed ones (Stokes, 2007). Hierarchical environments represent, in this context, a typical example of multiple personal, social and institutional constraints that shape not only creative choices and actions but also communication processes. This relates to our second argument, the fact that features specific for different levels of communicability, discussed above, need to be understood in relation to existing hierarchies. However, it would be a mistake to assume that highly hierarchical environments are associated mainly with Levels 1 and 2 of communicability and, as such, are detrimental to creative expression. Thirdly, and in connection to this, the sociocultural approach to both creativity and communication is built on this assumption that constraining contexts impact but do not determine creative and communicative processes. Indeed, as our research will illustrate, people living and working within hierarchical environments are capable of producing new meanings, including about hierarchical systems themselves, and of using their agency to ultimately shape them. 
In summary, the sociocultural approach to communication and creativity raises new questions concerning organizational change. Instead of considering the latter as initiated at an individual level (usually by managers or leaders) and explained in terms of psychological properties (like openness to experience, risk taking, etc.), it focuses our attention on communication processes as the locus for the emergence of novelty. The broad research question we address here is: how do constraining factors such as hierarchy hinder but might also foster creative processes within a public organization?

\section{METHOD}

\section{Participants}

The research presented here is interview based (Gaskell, 2002) and includes data from two employees from the Communication Department of a large public organization in Brasilia, hiring 9.713 employees distributed within 46 decentralized units in Brazil and several international offices. The organization is linked to the Ministry of Agriculture, Livestock and Supplies. The research presented here was developed within the Brazilian head office and its focus has been on the activities of Department of Communication because: the organization at all is focused on research and technology, thus, in innovation arising from creativity (Lahlou \& Beaudouin, 2016; Bruno-Faria, 2003); and the referred department is responsible for the internal and external flow of information - even in the interpersonal field - which can spread information and findings in an usual language and, by the other side, engage more employees - most of them scientists - in generating more knowledge and discoveries. Important to note, for contextualizing the theme of hierarchy, this organization was created in 1973, a period during which Brazil was a military dictatorship and the management model of big organizations, especially within the public domain, was (and to a large extent continues to be) based on hierarchization and departmentalization.

The choice of participants was deliberate, following the lead researcher's attendance of several group meetings in the organization. The two respondents had different positions and a unique perspective on the organizational environment, and they also were involved in different creative projects, briefly described below. This small number was chosen to develop a research model and possibly apply it later to other respondents and increase the generalization potential of the findings, especially by considering the individuals, their communication with each other and their other interactions with the organizational culture.

The first employee, ID 1, is a woman, 42 years old, journalist with an MBA in Communication Management. She had been working for 14 years in the organization and before that she had almost 10 years work experience in press offices of other public organi- 
zations. At the time of the research, she was working in the Coordination of Institutional Communication within the Department of Communication and, among other activities, was the editor of Journal $\mathrm{B}$, her main project.

The second, ID 3 , is a man, 40 years old, journalist and holding a PhD in Management with a focus on Marketing. He had been working for 9 years in the organization and, before this period, had another 11 years of work experience. At the time of the research, he was working in the Coordination of Market Communication within the Department of Communication and, among other activities, he was managing a campaign focused on food waste, his main project.

Both participants gave their informed consent to take part in the study, and the research project was approved by the Committee of Ethics in Research from the University of Brasilia. Furthermore, their participation was anonymized, as well as the name of the organization and of the journals produced inside it.

\section{Material}

Data was collected with the help of semi-structured interviews. The interview schedule was built following the lead researcher's attendance of several meetings within the organization and included questions regarding on-going projects of the participants. In addition, questions regarding creativity and creative processes as well as communication and organizational culture were included. Although the participants knew that the focus of the research was creativity, during the interview the concept itself was not used, unless the respondents referred to it. This choice reflects the sociocultural standpoint that creative activity is embedded within networks of people and practices instead of being associated with distinct and privileged positions or moments within the work process. Thus, not mentioning creativity in the questions and avoiding it during the conversations during which terms like change were used contributed for bringing spontaneously contexts favorable for creativity or not, rather than forcing the respondent to find or maybe force creative actions in their speeches.

Both interviewees were questioned about: How their new projects are developed and implemented in the organization; what constraints do they find; what openness exists to propose changes; what communication strategies they adopt to approve their ideas and to manage the projects in the way they plan, considering the involvement of other employees and organizational factors; and what is the impact of their projects and its products over the other employees and the organization. In the case of ID 3, some questions also concerned the partnership with other organizations and the communication from the researched organization to its 'outside'. 


\section{Procedure}

The empirical study was conducted between September and November 2016, with two follow-up discussions meant to clarify some of the topics covered in the interviews. The lead author participated first in weekly group meetings and then made three individual interviews with the participant ID 1 and, between the second and the third, two individual interviews with ID 3. The respondents were interviewed on multiple occasions and the resulting data included 3 hours 21 minutes of recorded interview with ID 1, who could clarify many important points in the beginning and in the end of this stage of the research process, and 1 hour 15 minutes of recorded interview with ID 3.

The analysis presented in this paper focuses on those segments of the interviews that deal with the issue of hierarchy. This choice is motivated first of all conceptually - as this theme sheds an interesting light on the relation between communication and creativity in an organizational context - and, second, pragmatically - as it is difficult to cover all the issues discussed with the participants in a single paper. However, the interviews in their entirety were used to contextualized information regarding the impact of hierarchy on creativity and communication by offering details about the general work environment, interactions between employees, job outcomes and expectations.

The analytical processes included the following stages:

1. The interviews were transcribed and read several times;

2. Segments concerning the conditions for creativity - with a focus on hierarchy and associated concepts - and the way participants defined and responded to existing constraints were selected for analysis;

3. Each of these selected segments were then thematically analyzed (Gaskell, 2002) based on the following questions: How are ideas received?; and How are meanings produced and possibly changed? These guiding questions generated the following list of themes - pressure, hierarchy, lack of money, bureaucracy, collaboration, freedom, and openness / open dialogue - each one with associated sub-themes.

4. The results of this thematic analysis were then considered within the general context of the relation between individual and organizational culture, particularly in view of when, where and how the individual's strategic plan meets the organizational one. This re-contextualization led to two main clusters that structure our presentation of the findings: 1. Management style; 2. Products and projects. Those ones are followed by the section Discussing the (interactions), which puts together some findings from the two main clusters and also add others to be discussed.

5. A final, descriptive narrative of the main themes and their context was created and is reported below in the Findings section, together with its interpretation of the ways in 
which interpersonal communication practices are perceived as more or less favorable for the creativity of employees.

To ensure quality in qualitative research (Bauer \& Gaskell, 2002), the analysis was done in iterative steps, as explained above, the views of both researchers on different themes were triangulated and they consistently engaged in reflexivity concerning the interpretation of the findings and their presuppositions regarding them.

\section{FINDINGS}

To ensure quality in qualitative research (Bauer \& Gaskell, 2002), the analysis was done in iterative steps, as explained above, the views of both researchers on different themes were triangulated and they consistently engaged in reflexivity concerning the interpretation of the findings and their presuppositions regarding them.

\section{Management style}

The first cluster refers to the management styles adopted by the two participants in relation to their ongoing projects and their collaborators. This over-arching theme sheds interesting light on the meaning of hierarchy and the ambivalence towards it, and on the dynamic between collaboration and competition.

As a first example of giving a more positive meaning to hierarchy, ID 1 mentioned resistance from the other units to the management of the Communication Department in what concerns the activities within the field of communication. In this case, resistance to the hierarchy was seen as potentially 'creative' behavior whose outcomes, from the perspective of those resisting, could be expressed in new work processes or products. Resistance is often understood as a tendency to "react negatively to change that is radical rather than gradual" (Eisenberg et al., 2010, p. 291) and this is the case here, where people might be embolden to resist also due to the relative security of their jobs as part of being hired by a public institution. Moreover, they tend to develop a certain degree of ambivalence towards the organization (Eisenberg, 1984), both wanting to participate in decision making and being suspicious of the intentions of upper management. A complementary explanation might be that participants could have a sense of losing autonomy, something that, despite being experienced as negative, could also trigger them to react differently to the management of the organization.

In relation to the expected outcomes of these acts of 'resistance', ID 3 said that "everybody has to feel like an employee of the organization, like working for the same organization" and thus their aim was to increase collaboration rather than competition among units. There are mixed findings in the literature concerning the impact of competition on creativity (Collins \& Amabile, 2006; Amabile, 1996) and ID 1 referred mostly to its 
negative consequences and to what was done to solve the problem. In a follow-up interview, this respondent identified the problem in terms of the segregation of employees and teams across different domains, which was making communication between them and the head office difficult. In response to this, the head office decided to create 'solid nucleons' and appoint people responsible for managing the communication within and between units. This might, on the one hand, be interpreted as a further loss of autonomy but, on the other, this might have been necessary in order to improve the flow of communication.

This reveals the interesting tension between constraints and creativity, between reduced autonomy and increased communication. In a big public organization like the one studied here, these kinds of changes have to be imposed somehow, otherwise they would not happen. In what concerns this ID 1 said:

So, actually, what we wanted to give to the units, by changing their names, their statute, was to say: 'Now we have a technical coordination of that process.', since they are, administratively, they are centralized. I think that, generally, the sensation was good. Of course, there were fights in the beginning, especially from the units' managers, when we created the nucleons, this thing of creating nucleons of communication, of putting people below the boss, was received with lot of resistance. Some units are resistant until this moment, but just a little bit.

As such, paradoxically, it is by adding to the hierarchy through an innovative action (at least from the perspective of the head office) that the environment can become more favorable for creativity through enhanced communication, collaboration and coordination of ongoing activities.

Analyzing this sequence of events through the prism of our model of communicability, we can notice that the proposed changes act at different levels of this typology. It can be argued that simply opening new channels of communication doesn't necessarily change the 'old' meanings of the messages being communicated. As such, a first level of communicability can be maintained, as exemplified in the last interview excerpt. However, by increasing the flow of communication, this change also opens up the possibility of passing to the second level, because it increases the number of interactions and the potential to 'improve' the messages, as also exemplified in the last interview excerpt. This also sets the scene for the third and potentially the fourth level of communicability if and when these communication channels become more effective at creating an atmosphere of openness and freedom among employees and encouraging them to listen to each other while proposing unique perspectives and even sharing their emotions. These changes would all depend, however, on the degree of institutional scaffolding for these processes 
and the two respondents expressed their hope that this will be the trajectory followed by the organization.

As an illustration of these expectations we can refer to the production of journal $B$ by ID 1, a process that depends on the collaboration between different units. For this respondent, such management actions could contribute to an important progress when it comes to the novelty, originality and number of ideas produced for the journal. During its edition, she said she "indicates which Organization unit should collaborate, according to its specificity and ask if they have some content to send.". Once she got collaborations from 18 different units, number attributed to the relevance of the the theme precautionary measures against Aedes Aegypti to the employees of the organization at all, thus, to their motivation to collaborate, in order to keep their health. This particular edition of Journal B was so rich due to the diversity and richness of the contributions. In conclusion, when it comes to management styles it is important to understand them not only in terms of immediate outcomes they produce (e.g., a certain change in the level of communicability within the organization) but also in terms of the horizon of expectations they create. These, in turn, have an impact on existing hierarchies and, as exemplified here, could actually use the hierarchical system and its affordances to promote gradual (not abrupt) and yet meaningful changes.

\section{Products and projects}

In the interviews, respondents also discussed specific products or projects, including journal B, aforementioned. They also identified the kinds of management actions that would contribute to the quality of both collaborations and overall creativity. When it comes to journal B, ID 1 referred to actions such as: a) Establishing but also negotiating deadlines for receiving contributions; b) Measuring and monitoring access to the online version, analyzing reader comments and systematizing the data to support further decisions; and c) Asking for contributions and more active participation especially since the purpose of the journal is to be made by employees for employees (different from the much more 'vertical' communication, from management to employees, specific for journal A).

The setting of deadline is a good example of the equivocal impact of a certain hierarchical decision on creativity. On the one hand, it could enhance productivity while, on the other, it can hinder creativity by generating inhibition and unwillingness to participate. These different outcomes need to be understood in context, as they will depend on other 'variables' such as working routine, the necessity to develop other tasks, changes in the decisions of superiors, as well as employee characteristics such as mood, emotional state, motivation for the task, and so on. 
Systematizing the data from reader comments can offer ID 1 concrete support for her arguments in relation to colleagues and superiors and she already managed to achieve some changes based on this (e.g., changing the frequency of the journal from quarterly to bi-monthly, and her intention is to make it a monthly journal). The way in which the participant implements these changes will arguably establish different levels of communicability in relation to upper management. The use of evidence-based arguments could lead to generating new meanings or, on the contrary, could reinforce existing understandings on behalf of her superiors. ID 1 is thus in the process of experimenting with different approach in her communication, trying to move the discussion towards higher levels of communicability that support the changes she is aiming for (among others, eliminating the print version of journal B).

For example, ID 1 mentioned during the interview that she had to accept a topic for the journal being blocked by the presidency. Such a hierarchical move is typical for level 1 communicability, based on reinforcing the power of one discourse of point of view over another. It also illustrated the negative sides of hierarchical systems. However, by preparing to show the results of her research in order to support her vision of the journal, ID 1 deliberately tries to create a new communicability context and cultivate her own freedom and autonomy, paradoxically by using 'tools' put at her disposal through a hierarchical decision (i.e., to conduct systematic research). What she expects is that these tools will allow her to implement the desired changes and also cultivate a different type of relationship to her superiors, once described by the third and fourth levels of communicability in our typology. The interview with ID 3 also supports this view, when he mentioned, for example that:

in a research organization like this, the communication has to work very closely to the research, and the work of communication, many times, is similar to the one of research, which means that the communication professional must also have the expertise to analyze data, work with big data.

This, according to both participants, is very important for how they position themselves and even how they 'survive' within the organization. In fact, ID 3 refers to communicability as a resource in any organization, supported by personal skills to interpret data and anticipate situations, in taking management decisions and initiating new projects. However, these skills can be effective only if they are understood and valued within the particular culture of the organization and, thus, if the employee knows how to manage his or her interpersonal communication to propose changes. Such an atmosphere would create a climate of openness specific for the higher levels of communicability we previously identified and this is a kind of atmosphere both our respondents are striving towards. 


\section{Discussing the (inter)actions}

The actions described and discussed in the findings section suggest that the meaning of hierarchy is changeable and fundamentally defined by ambivalence since it can act both as a constraint or facilitator. In this final section, we outline different usual or ordinary actions taken by employees to produce changes in the organization.

When the head office created the nucleons of organizational communication in other units in Brazil, the actions of ID 1 and her team were aimed at make this new hierarchy favorable for interpersonal communication and creativity. The latter can be seen as a combined outcome of giving each unit a set of directions while allowing them the autonomy to develop an internal team and coordinate their work. This reflects the potential for conflict but also collaboration between the agency of individuals or teams and the structural constraints of the organization.

The same tension can be observed when she sets, as editor, deadlines for contributions to be received for the journal. Once again, her actions are considered positive from her perspective, as taking advantage of the close hierarchy of the organization. However, this hierarchical decision remains ambivalent from the perspective of the other employees who can be stimulated to contribute but could also consider this a burden, depending on the management styles used by ID 1. Furthermore, on the one hand she said:

I ask contributions for the Journal B, my colleague asks for the Journal $A$, the other, to the Magazine, the other, to the news agency, the other, to the event he/ she is organizing (...). Then the employee, sometimes the only responsible for the communication in the unit or sharing this role with just one colleague, feels overwhelmed because he/she still have the current tasks of the unit.

And on the other hand:

1. Sometimes it [the indication of the unit which should collaborate] is not effective and I have to keep calling (...)" and when this doesn't work either, she publishes a ranking with the number of participations of each Organization unit in the paper, over a year, turning public - internally - the actuation of the units and its employees. This is what she calls "provocative exposition" and constitute the innovative way she found to get collaboration.

2. During the production of one edition the situation got worse before the deadline and she asked help from her coordinator - of internal communication - who sent a message to the other units asking collaboration. In another occasion, instead of ID 1, the same coordinator had to say to a journalist from another unit that the text sent for the new was not adequate. She is, thus herself, in a double position in relation to the power (Elmholdt et al., 2016) embedded within hierarchies because on the one hand 
she can understand some resistances and on another hand, she finds ways of making other employees collaborate with the work. When the presidency refused a topic for Journal B, she said "It was necessary to obey", in spite of expressing doubt by saying "I don't know if we misjudged that topic (...). The theme has already been diffused externally. (...) It became sensible now." and also considering the decision from the upper management a surprise even because the topic had been demanded. In this example, hierarchy was perceived as constraining and, at the same time, she tried to understand the whole context, the involvement of other people and the organizational culture. However, in different occasions, ID 1 can propose changes even to the communication flow of the organization, something that builds on a certain degree of openness of the organization itself.

Enhanced collaborations and good conviviality are the outcomes of those actions that build on hierarchy as a facilitator for change and for turning the environment more favorable towards creativity. At the same time, there are a lot of changes to be made before relations are characterized as an open dialogue and ID 3, for instance, complained about the vertical, uni-directional flow of communication often adopted by upper management. In his words:

Sometimes the communication is good between that 'industry floor' and the supervisors, but not with the manager and less with directors and presidents, who don't walk much within the organization. This is a problem I mention here, in the meetings. I think they (...) should walk more inside the Organization to feel it, its organizational culture, and take some management decisions better. (...) this [the hierarchization] is very bad in Brazilian management (...). Thus we have to create strategies which pass through communication and can possibly change this organizational culture, which is a long term work. Maybe as a consequence, the manager of the communication department included on her agenda hearing each employee for one hour and far from its coordinator.

According to the excerpt from ID 3, the current changes can also pave the way for others, depending on the actions of the employees themselves and, we would add, the way they communicate with each other. The strategies mentioned before can constitute adaptive reactions to environmental constraints, in order to find ways of developing new, interesting projects, which would allow the 'survival' of the profession. The attempt of ID 3 to initiate this change is based, for example, on actions like openly sharing his opinions about management, work projects and products in collective meetings, and finding new ways of managing projects in and for the organization. For doing this, he relies on other employees, first from the Communication Department, but on his knowledge of the organizational culture, including its bureaucracy and the possibilities to question it. Organiza- 
tions are intrinsically aversive to change (Lahlou \& Beaudouin, 2016) and yet, by changing the meaning of existing rules and hierarchies, employees do have the possibility at least of subverting this resistance to change and its underpinning values.

In studying this process, it is important not to 'localize' the potential for change within individuals, for example within their personal traits or cognitive processes working in isolation (Glăveanu, 2010). These traits and skills need to be understood in context, especially in the way they are developed and become manifest at the workplace. As we argued here, from a sociocultural perspective, the potential for creativity doesn't reside in individual minds but rather, in the relations between people: Within acts of communication and contexts of communicability. These notions make us pay more attention to environments favorable for creativity rather than to creative people, taken separately. 'Creative environments', however, cannot be taken for granted as they represent the outcome of joint efforts, usually spread across time, to renew existing structures not by working simply against them but oftentimes with or through them.

The contribution of the organization to this renewal rests in adopting a series of steps that contribute to an enhanced level of communicability between its members:

1. Being open to approving new ideas and motivating people to produce them;

2. Improving these ideas by helping people collaborate with each other and also enhancing departmental dialogues;

3. Valuing ideas and disseminating them while being sensitive to the reactions of different audiences and allowing them to participate in further acts of creativity.

In summary, creativity depends on communicability from the first level of keeping old meanings up the fourth, described by the emergence of novelty. While employees constantly aim towards reaching this level, there are numerous challenges in implementing it. Hierarchies are usually 'blamed' for the failure of opening and creatively sharing ideas within the organization. However, as we tried to argue here, it is by changing their meaning and value, from constraint to facilitator, that a deeper understanding of the organization and the possibilities to act within it can be achieved.

\section{CONCLUSION}

This article started from the question of how different actions can turn a work environment more favorable for creativity by possibly changing the meaning of hierarchy. Based on the typology of communicability levels proposed at the beginning, we assume from a theoretical perspective that level 1 of communicability, characterized by the imposition of certain meanings, hinders creative expression, that level 4 , based on open dialogues, is conducive for it, while levels 2 and 3 can be more or less favorable depending on context. Look- 
ing concretely at the organization studied here through the lenses of two employees, it would be tempting to think that a highly hierarchical environment harms both creativity and communication. However, our data paints a different, much more complex picture by showing that hierarchy can be used, in certain circumstances, as a resource for change and that creativity is not rooted in a particular level but shaped by the movement between levels, often guided by the expectations of employees and their interactions with colleagues and the upper management.

It is also important to situate these dynamics within their broader cultural and historical context. For instance, the strong hierarchies that often characterize large public organizations in Brazil can be traced back to centuries of colonization and decades of an authoritarian military regime that ended in the 1980s. At the same time, it is important to recognize individual agency especially within work organizations where, for instance, the participants interviewed for this research are gradually trying to change the organizational culture towards more openness and autonomy. The acts of creativity referred to above both lead to and depend on implementing such long-term changes. The success of this process depends on superiors communicating directly and properly with their employees, trying to reach higher levels of communicability and, through this, much more than just informing or exchanging information, making organizational communication an activity open to differences in perspective and new meanings. Otherwise, there is not much dialogue, the way the employees think and feel is not properly considered, and the communication in the organization is poor and incomplete.

This study has its own limitations, starting from the very small sample size and the fact that we rely almost exclusively on the discourse of the participants to understand organizational realities. However, it is important to note that the interviews came after a period of participant observation and also that the aim of the study is not to generalize these findings but to open the way for a deeper analysis and for raising new questions regarding the relations between communication patterns, hierarchy and creativity. By introducing the notion of communicability and using it to analyze the data, we hope to have shed new light on common practices and their potential to introduce change and new meanings within an organizational setting. Future research can use this preliminary typology to study other contexts, perhaps also conducting a comparative analysis of public and private organizations or of organizations from different cultures. In the end, our hope is that, through such studies, we can offer employees and leaders the necessary tools to understand, reflect on and enact the changes they would like to see within their organization by effectively using the communication and cultural resources at their disposal for the benefit of many. 


\section{REFERENCES}

Amabile, T. (1996). Creativity in context. New York: Perseus Books.

Bakhtin, M. M. (1997). Estética da criação verbal (2a ed). São Paulo: Martins Fontes.

Bakhtin, M. M. (1981). The dialogic imagination: Four essays. Austin, TX: University of Texas Press.

Barron, F. (1995). No rootless flower: An ecology of creativity. Cresskill, NJ: Hampton Press.

Bauer, M. W., \& Gaskell, G. (2002). Qualidade, quantidade e interesses do conhecimento Evitando confusões. In M. Bauer, \& G. Gaskell (Eds.), Pesquisa qualitativa com texto, imagem e som: Um manual prático (pp. 17-36). Petrópolis: Vozes.

Bruno-Faria, M. de F. (2003). Criatividade, inovação e mudança organizacional. In S. M. V. Lima (Ed.), Mudança organizacional: Teoria e gestão (pp. 111-141). Rio de Janeiro: FGV.

Choi, J. N., Anderson, T. A., \& Veillette, A. (2009). Contextual inhibitors of employee creativity in organizations. Group \& Organization Management, 34, 330-357.

Collins, M. A., \& Amabile, T. (2006). Motivation and creativity. In R. J. Sternberg (Ed.), Handbook of creativity (pp. 297-312). New York: Cambridge University Press.

Curvello, J. J. A. (2012). Comunicação interna e cultura organizacional. Brasília: Casa das Musas.

Eisenberg, E. M. (1984). Ambiguity as strategy in organizational communication. Communication Monographs, 51, 227-242.

Eisenberg, E. M., Goodall JR., H. L., \& Trethewey, A. (2010). Organizational communication: balancing creativity and constraint. (6th ed.). New York: St. Martin's Press.

Elmholdt, C., \& Fogsgaard, M. Power. (2016). In V. P. Glăveanu, L. Tangaard, \& C. Wegener (Org.). Creativity - A new vocabulary (pp. 111-120). Hampshire: Palgrave Macmillan.

Gaskell, G. (2002). Entrevistas individuais e grupais. In M. Bauer, \& G. Gaskell (Eds.), Pesquisa qualitativa com texto, imagem e som: Um manual prático (pp. 64-89). Petrópolis: Vozes.

Gillespie, A. (2010). The intersubjective nature of symbols. In B. Wagoner (Ed.), Symbolic transformation - The mind in movement trough culture and society (pp. 23-37). New York: Routledge.

Glăveanu, V. P., Gillespie, A., \& Valsiner, J. (2014). Rethinking creativity: contributions from social and cultural psychology. Didcot, UK: Routledge.

Glăveanu, V. P. (2010). Paradigms in the study of creativity: introducing the perspective of cultural psychology. New ideas in psychology, 28 (1), 79-93. 
Glăveanu, V. P. (2012). Rewriting the language of creativity: The five a's framework. $R e-$ view of General Psychology, 3, 1-13.

Glăveanu, V. P. (2016). Things. In V. P. Glăveanu, L. Tangaard, \& C. Wegener (Eds.). Creativity - a new vocabulary (pp. 164-171). Hampshire: Palgrave Macmillan.

Glăveanu, V. P., Lubart, T. (2014). Decentring the Creative Self: How Others Make Creativity Possible in Creative Professional Fields. Creativity and Innovation Management, 46(1), 29-43.

Juelsbo, T. (2016). Rules. In V. P. Glăveanu, L. Tangaard, \& C. Wegener (Eds.). Creativity - A new vocabulary (pp. 137-146). Hampshire: Palgrave Macmillan.

Lotman, I. (1978). A estrutura do texto artístico. Lisboa: Editorial Estampa.

Lahlou, S., \& Beaudouin, V. (2016). Creativity and culture in organizations. In V. P. Glăveanu (Ed.), The Palgrave handbook of creativity and culture research (pp. 475-498). London: Palgrave Macmillan.

Ludwig, A. M. (1992). Culture and creativity. American Journal of Psychotherapy, 46(3), 454-469.

Lubart, T. (2007). Psicologia da criatividade. Porto Alegre: Artmed.

Machado, I. (2003). Escola de semiótica. São Paulo: Ateliê Editorial/Fapesp.

Marcondes Filho, C. (2010). O princípio da razão durante: O conceito de comunicação e a epistemologia metapórica. São Paulo: Paulus.

Marcondes Filho, C. (2016). Teorias da comunicação hoje. São Paulo: Paulus.

Martino, L. C. (2001). De qual comunicação estamos falando? In A. Hohlfeldt, L. C Martino, \& V. V. França (Eds.), Teorias da Comunicação: Conceitos, escolas e tendências (pp. 11-25). Petrópolis, RJ: Vozes.

Negus, K., \& Pickering, M. (2004). Creativity, communication and cultural value. Londres: Sage.

Paulus, P. B., Dzindolet, M. T., \& Kohn, N. W. (2012). Collaborative creativity: Group creativity and team Innovation. In M. D. Mumford (Ed.). Handbook of organizational creativity. (pp. 327-357). Taramani, Chennai: Elsevier.

Sternberg, R. J., \& Kaufman, J. C. (2010). Constraints on Creativity: Obvious and not so obvious. In J. C. Kaufman, \& R. J. Sternberg (Eds.), The Cambridge handbook of creativity (pp. 467-482). New York: Cambridge University Press.

Stokes, P. D. (2007). Using Constraints to Generate and Sustain Novelty. Psychology of Aesthetics, Creativity, and the Arts, 1(2), 107-113.

Thayer, L. O. (1973). Comunicação e teoria da organização. In F. E. X. Dance (Ed.), Human communication theory - Original essays (pp. 94-148). São Paulo: Cultrix. 
Tejerina, J. C., \& Rosa, A. (2007). Psychology within time. Theorising about the making of sociocultural psychology. In J. Valsiner, \& A. Rosa (Eds.), Cambridge handbook of socio-cultural psychology (pp. 62-81). Cambridge: CUP.

Valsiner, J. (2007). Culture in minds and societies: Foundations of cultural psychology. New Delhi: Sage Publications.

Vigotski, L. S. (1998). Pensamento e linguagem. (2a ed.). São Paulo: Martins Fontes.

Vigotski, L. S. (2000[1929]). Psicologia concreta do homem. Educação e Sociedade, 71, 23-44.

Wallon, H. (1979). Psicologia e educação da criança. Lisboa: Editorial Vega.

Corresponding author at: Asdrúbal Borges Formiga Sobrinho, Comunicação, Universidade de Brasília, Campus Universitário Darcy Ribeiro, Brasília-DF | CEP 70910-900. E-mail: asdrubal@uol.com.br 